\title{
Erratum to: Effectiveness of a drain in surgical treatment of sacrococcygeal pilonidal disease. Results of a randomized and controlled clinical trial on 803 consecutive patients
}

Marco Milone - Mario Musella • Giuseppe Salvatore •

Maddalena Leongito • Francesco Milone

Published online: 15 June 2011

(C) Springer-Verlag 2011

Erratum to: Int J Colorectal Dis

DOI 10.1007/s00384-011-1242-4

Due to a mistake occurred during the proofs correction, correct names in a wrong position appear now in the medline.

The correct names list should be: M. Milone, M. Musella, G. Salvatore, M. Leongito, F. Milone.

The online version of the original article can be found at http://dx.doi. org/10.1007/s00384-011-1242-4.

M. Milone $(\bowtie) \cdot$ M. Musella $\cdot$ G. Salvatore $\cdot$ M. Leongito •

F. Milone

Department of Surgical Sciences, Orthopedics, Trauma and

Emergency, University of Naples "Federico II",

Naples, Italy

e-mail: milone.marco@alice.it 